\title{
Care in the Cage: Materializing Moral Economies of Animal Care in the Biomedical Sciences, c. 1945-
}

Link to publication record in Manchester Research Explorer

\section{Citation for published version (APA):}

Kirk, R. G. W. (2016). Care in the Cage: Materializing Moral Economies of Animal Care in the Biomedical Sciences, c. 1945-. In K. Bjørkdahl, \& T. Druglitrø (Eds.), Animal Housing and Human-Animal Relations Politics, Practices and Infrastructures Routledge.

http://www.tandfebooks.com/userimages/ContentEditor/1479306074853/9781138854116_oaChapter11\%20(0000 0003).pdf

\section{Published in:}

Animal Housing and Human-Animal Relations Politics, Practices and Infrastructures

\section{Citing this paper}

Please note that where the full-text provided on Manchester Research Explorer is the Author Accepted Manuscript or Proof version this may differ from the final Published version. If citing, it is advised that you check and use the publisher's definitive version.

\section{General rights}

Copyright and moral rights for the publications made accessible in the Research Explorer are retained by the authors and/or other copyright owners and it is a condition of accessing publications that users recognise and abide by the legal requirements associated with these rights.

\section{Takedown policy}

If you believe that this document breaches copyright please refer to the University of Manchester's Takedown Procedures [http://man.ac.uk/04Y6Bo] or contact uml.scholarlycommunications@manchester.ac.uk providing relevant details, so we can investigate your claim.

\section{OPEN ACCESS}




\section{Animal Housing and Human-Animal Relations}

Politics, Practices and Infrastructures

\section{Edited by Kristian Bjørkdahl and Tone Druglitrø}

First published 2016

ISBN: 978-1-138-85411-6 (hbk)

ISBN: 978-1-315-72233-7 (ebk)

\section{Care in the Cage}

Materializing Moral Economies of Animal Care in the Biomedical Sciences, c.1945-

Robert G. W. Kirk

(CC BY-NC-ND 3.0) 


\title{
11 Care in the Cage
}

\author{
Materializing Moral Economies of \\ Animal Care in the Biomedical Sciences, \\ c.1945-
}

Robert G. W. Kirk

This chapter adopts a historical perspective to explore how material infrastructures have structured human-animal relationships within the biomedical "animal house," c.1945 to the present. ${ }^{1}$ Following what has been characterized as the "ontological turn" in science studies (for example, Woolgar and Lezaun 2013), it is shown that material infrastructures serve to structure the multiple values that have informed and shaped human-animal relations within the experimental biomedical sciences (cf. Mol 2002; Law and Singleton 2005). By focusing on enactment as opposed to "knowledge" (or epistemology) alone, specific infrastructural objects (such as the animal cage) are revealed to be multiple (as opposed to singular objects). Such a perspective is one step toward empirically grounding Donna Haraway's contention that 'the 'shared conditions of work' in an experimental lab[oratory] make us understand that entities with fully secured boundaries called possessive individuals (imagined as human or animal) are the wrong units for considering what is going on" (Haraway 2008, 70). Taking up this observation, and expanding it to include material infrastructure, reveals how multispecies sociocultural relations performatively shape and are shaped by the physical infrastructures that make up lived relations and shared labor in the animal house and laboratory. Collectively, enactments of "multispecies relations" are taken to form a dynamic, situated and emergent "moral economy" wherein the moral economy cannot be separated from factors that would properly be associated with a political economy of animal-dependent experimental science.

The concept of "moral economy" has been profitably imported into science studies (for example Kohler 1994; Strasser 2011) where it has been used to describe and contrast the systems of values that govern the exchange of knowledge and commodities within different scientific communities. Such usage, however, emphasizes the analysis of the values that shape legitimate exchanges within human cultures as opposed to exchanges and relations between human and nonhuman organisms. Thus Kohler charts how practices of exchanging drosophila mutants shaped a unique "moral economy" shaping the research culture that grew about this organism. But this usage has little to say about moral relations beyond the human. Kohler exclusively examined how values governing commodity exchange operated to shape human communities; the question of how 
researchers construed their moral relationship to the fly was left unasked. In contrast, Daston presents a different understanding of the moral economy, which is more concerned with exploring how notions of scientific objectivity "are not simply compatible with moral economies; they require moral economies" (Daston 1995, 3). Ways of knowing within science, contrary to common-sense distinctions, operate through economies of affects and emotions that are entirely compatible with and necessary to "rational" scientific practices such as quantification and standardization. Daston's "moral economy," therefore, appears compatible with a focus on performance and enactment. For Daston, a moral economy operates as a balancing system providing structure to the "web of affectsaturated values" which shape scientific work through virtue of being tied to specific activities that "anchor and entrench but do not determine it" (Daston $1995,4)$. Within animal-dependent experimental sciences, the performance of animal care has increasingly formed the core of the moral economy, shaping, and being shaped by, the material infrastructure of the animal house. Which is to say moral concerns focused on the performance of care have been enacted through material infrastructure. Here, then, Daston's foregrounding of affects and emotions serves as a means to view the "moral economy" not as exclusively human but rather as a multispecies concern.

As such, this chapter explores how multiple and often conflicting values and concerns centered on animal care have taken form within specific moral economies, become materialized within physical infrastructures of the animal house, and thereby constituted new values and concerns. The performance of animal care, in this sense, is shown to have operated to constitute the object of care and has done so by materializing affect-saturated values within physical infrastructure. Such an argument draws on an emerging literature responding to Bruno Latour's invitation to seek the "missing mass of morality" (Latour 1992, 233). For Latour, "morality ... like science and technology, is a heterogeneous institution constituted from a multiplicity of events, which depends at the same time on all modes of existence and in part ... on the arrangement of technical apparatus" (Latour 2002, 254). Accordingly, Latour challenges the perception that technologies belong to the realm of means whilst morality addresses the question of ends. Within the biomedical sciences, the experimental use of animals raises a plethora of moral questions but answers rarely examine the extent to which morality is built in to the physical infrastructure and technologies of the animal house and laboratory. The laboratory animal cage, for instance, is not merely a means to an end. Rather, it can be understood to be a material instantiation of the conflicting and complex values that inform and shape the practice and ends of animal-dependent science. Accordingly, the physical infrastructure of laboratories and animals houses can be viewed as simultaneous means and ends, operating to materialize, stabilize and enact moral economies. Rather than purely functional, biomedical infrastructures such as the laboratory, animal houses, and animal cage, instantiate multiple and varied sociocultural, political, moral, economic, and scientific values, in forms suitable to secure locally determined ends. More specifically, the laboratory animal house and animal cage can be 
viewed as macro and micro physical instantiations of care practice. Just as the material form of Latour's desk drawer mechanism compels him to obey a moral principle, so too have animal cages embodied and expressed specific understandings of care. Understandings which, in turn, shape the possibilities of the relationships of multispecies concern that may or may not be shared within the animal house and laboratory.

This argument is developed through two complementary sections that explore how, why, and to what consequence a specific understanding of laboratory animal care, which prioritized animal health, was enacted through practices that came to be instantiated within the macro architectural infrastructure of the laboratory animal house (section 1) and the micro infrastructure of the animal cage (section 2). A final section discusses the implications of the historical entanglement of material infrastructures and care practices, relating this analysis of how moral economies of care have been enacted through material infrastructures to recent calls to explore new possibilities for acting with care within shared liveable worlds (Puig de la Bellacasa 2011).

\section{Care in the Animal House: Institutionalizing the Moral Economy of Animal Care}

Significant components of contemporary laboratory animal care practice emerged with and through twentieth-century historical trends that have been collectively characterized as "biomedicalization," being processes that place an intensive focus on the promotion of health through new biopolitical economies. Biomedicalization typically emphasizes the capacity of science and technology to transform bodies and produce new individuals and collectives (Clarke et al. 2010). Early twentieth-century laboratory animal care focused on health, specifically the need to prevent infectious disease (illustrating how biomedicalization operated across species boundaries). This is evident in the work of William LanePetter, an early proponent of the professionalization of laboratory animal care in the post Second World War period. Lane-Petter argued that

the standard of laboratory animal accommodation to be aimed at is nearer to that of a hospital than of a farm, and terms like "farm" and "stable" should not be found in the vocabulary of this discipline [of animal care].

(Lane-Petter 1959, 182)

In calling for a shift from the farm to the hospital, Lane-Petter was highlighting the specialist practices of breeding, husbandry, and care that he believed were necessary for the production of animals suitable for scientific use. As will become clear, it is not incidental that Lane-Petter communicated his vision of animal care through reference to physical architecture. Lane-Petter's choice of the hospital as the architectural model for the animal house derived from his principal definition of animal health and welfare in terms of freedom from infection and disease. The definition of animal health in terms of infection provides a paradigmatic example 
of how animal care enacted a moral economy that aligned animal welfare with animal health, scientific utility, fiscal costs and sociocultural values. Latent infection within laboratory animal stocks risked undermining experimental procedures. For instance, pathological manifestations of infection might be mistakenly thought to be a consequence of the experimental interventions resulting in the resultant knowledge being misleading and impossible to reproduce. Furthermore, infection could manifest as disease so rapidly that animals frequently failed to survive experiments in sufficient numbers to provide statistically meaningful results. At the same time, endemic infection had significant economic consequence as animals lost to disease were a wasted investment proving costly in research time and labor. The economic burden was intensified by the common practice of routinely using more animals than was statistically required to ensure enough lived to gain viable results (more animals meaning higher costs). Managing the problem of infection was particularly challenging as pathogens were often "latent," displaying no obvious visible signs until triggered by an environmental change to manifest as overt disease. In the absence of rigorous epidemiological knowledge, animal care was enacted through spatial and material techniques such as "quarantine" that were increasingly built into animal house and laboratory infrastructures. ${ }^{2}$ As regimes of infection control became institutionalized within architectural design, animal care was gradually "materialized."

One consequence of the alignment of animal health to scientific utility was to raise the status of the animal house to the point that substantial investment in its infrastructure became desirable. ${ }^{3}$ The Philadelphia-based Wistar Institute's rat house, for example, purpose built in 1922, enacted a moral economy of animal care through its physical infrastructure. The architecture of the building discouraged internal movement by providing an external entrance/exit to each room (making use of open air to minimize risk of cross-infection). This also allowed individual rooms to be effectively isolated should infections be discovered (Greenman and Duhring 1931).

By mid-century, animal care practice was inseparable from the wider infrastructure of the animal house as it was established practice for different animal stocks to be isolated in numerous small rooms to enhance health by minimizing cross-infection (Howie 1956). Writing in 1950, Leonell C. Strong of the Jackson Laboratory advised "it is extremely important to maintain a colony ... by themselves and not in contact with any other species of animals ... no new animals should be brought into the laboratory from any outside source" (Strong 1950, 8081). Microbial loads and tolerances were inherited in the first instance and thereafter considered to be fragile ecologies which, in practice, determined which animal populations could be safely introduced and mixed and which could not. As pathogens such as "ring worm" were found to be zoonotic, the human body together with its microbial load became a key determinant of animal health, increasingly subjected to control through spatial and material distancing (albeit a distancing premised upon and emphasizing the shared microbial loads of human and animal). This approach reached a zenith with the development of isolator technologies to establish and maintain secure microbial environments; making 
possible the creation and maintenance of germ-free and specific-pathogen-free animals (Kirk 2012). These new techniques, developed and institutionalized through the 1950s, brought into being new forms of life with entirely defined microbial relations known variously as "clean," "pathogen free," "specific pathogen free," "disease free," and "gnotobiotic" (known life) animals. In contrast to conventional animals, these were presented as "sophisticated" having been "altered from, deprived of, primitive simplicity or naturalness" to become "the healthy animals we have been looking for for years" (Lane-Petter 1966, 54; Lane-Petter 1963, 55).

One of the earliest implementations of "pathogen free" breeding techniques in Britain was a purpose-built pharmaceutical research facility constructed for Imperial Chemical Industries Ltd. (ICI) on a 350-acre rural site at Alderley Park (Cheshire) in 1958. Having conducted a global survey of trends in biomedical institutions, ICI designed their entire site about principles of microbial control. Animal work was divided into three categories, spatially separated via the quarantine principle. Laboratories for "non-infectious" and "infectious" research were located at opposite ends of the main building linked by basic chemistry laboratories intended to act as a barrier between the two (Figure 11.1).

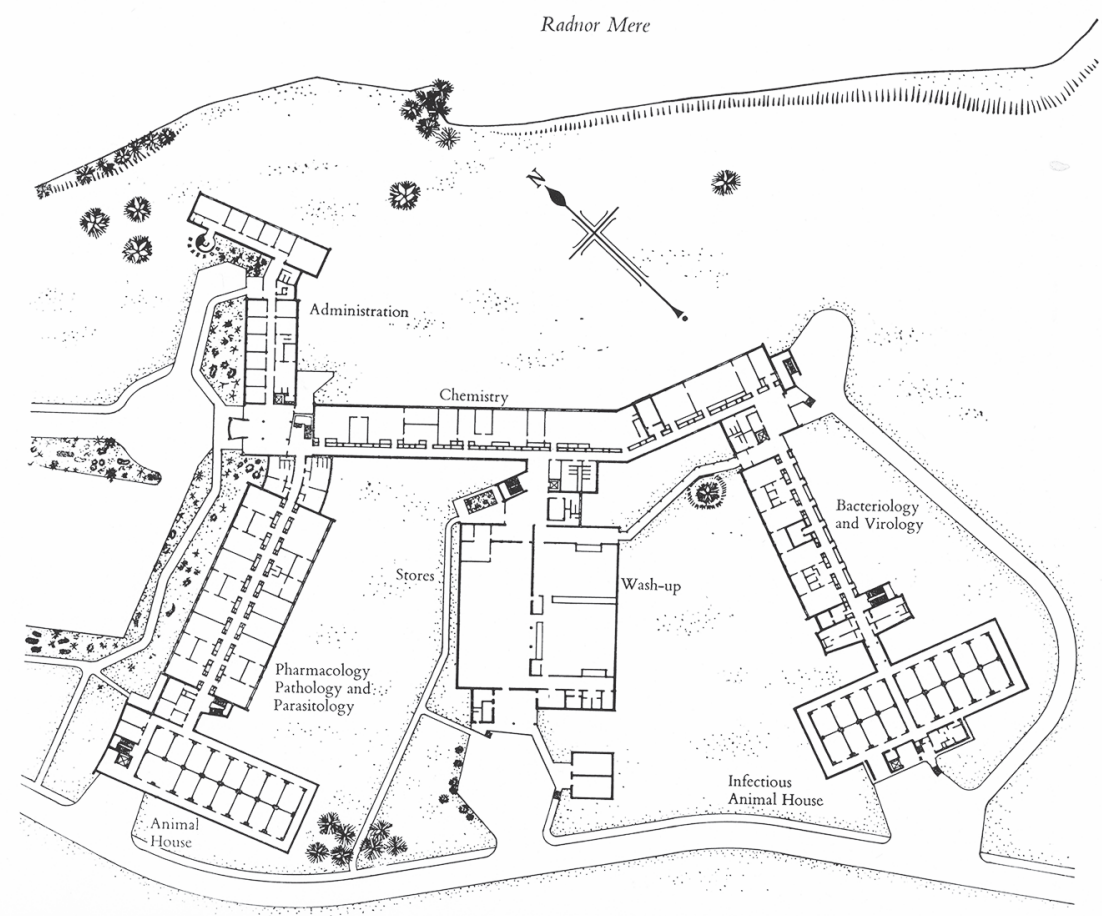

Figure 11.1 ICI main research facilities

Source: I.C.I., n.d. 
Outputs from chemical and pharmaceutical research would flow down the east (non-infectious) or west (infectious) wing as appropriate. By removing the need for movement between the infectious and non-infectious research wings the building worked to minimize the risk of accidental transferal of microbes thereby promoting animal health. Within the building, internal passageways were minimized with entry to animal rooms restricted to outside doors. Floor-level physical barriers were incorporated to prevent escaped animals from roaming too far (Figure 11.2). Different animal rooms were color-coded to visibly alert workers to the fact they had moved from, for example, rooms where clean animals were being prepared for experimental use ("white") to laboratories where animals had been experimentally infected with pathogens dangerous to humans ("red"). In these ways, the building infrastructure actively shaped behavior enacting the moral economy of laboratory animal care.

Accordingly, the animal production unit was located some distance away within a 10 -acre glade shielded by forestry with the surrounding lands protected from vermin and other wild animals by secure double fencing fitted with a double gated entry point (Figure 11.3).

The "Breeding Unit" was designed to maintain a highly controlled and microbially secure environment for the production of "Specific Pathogen Free" (SPF) animals. The building was physically divided into two areas, "dirty" and "clean," with all movement from one to the other regulated by mechanical barriers and rigorous decontamination controls. The windowless clean area had no "natural"

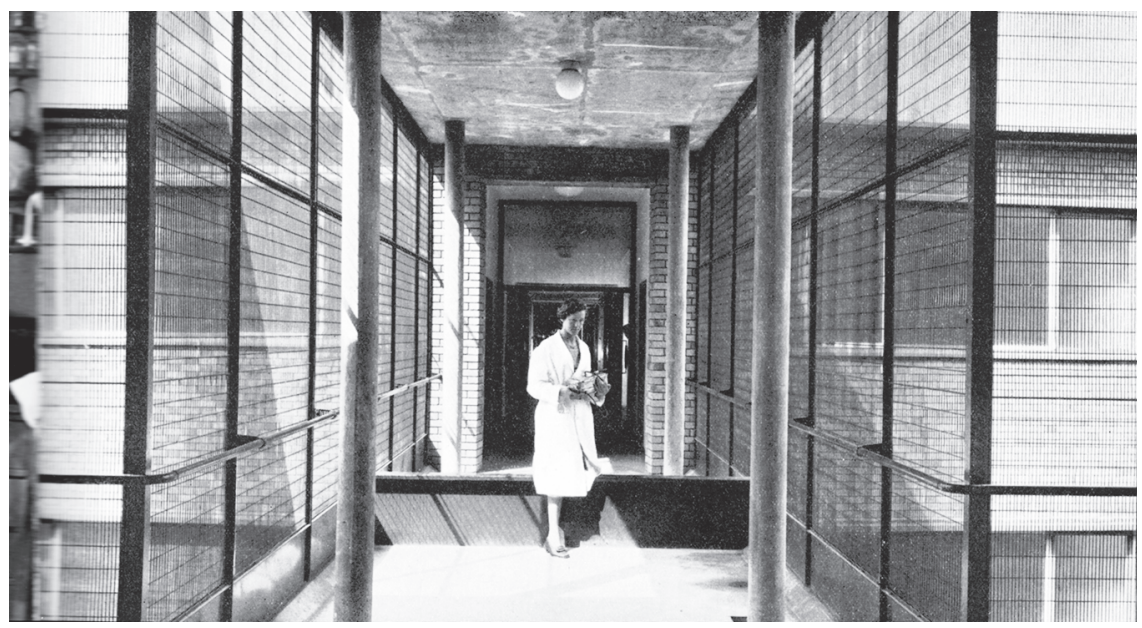

Figure 11.2 Entry to animal rooms was only possible from a perimeter open-air corridor (fine netting prevented wild animals and birds from gaining entry to the corridor). Strategically placed material barriers allowed human movement whilst preventing undesired rodent movements

Source: I.C.I., n.d. 




Figure 11.3 ICI site map illustrating spatial separation of SPF Animal Breeding Unit from research laboratories

Source: I.C.I., n.d.

source of ventilation or light. Air intake was artificially managed, drawn from a high altitude, and filtered, heated, conditioned and circulated throughout the building at a fixed rate of ten complete turn-overs per hour being additionally filtered on entrance/exit of each room. Material goods could only enter the clean area by passing through double-locked autoclaves designed so that the inner doors mechanically locked once an outer door was opened until an automated sterilizing cycle had completed. In this way, food and water were rigorously sterilized, with the latter delivered to animals via a purpose-designed automated watering system integrated into the cage racking. A similar system automatically flushed animal housing units with aseptic water washing away feces and other waste, again illustrating how the moral economy of care became integrated into the infrastructure of the building. 
Human access to the clean area was also managed by infrastructural design (Davey 1959). Staff entered through a separate, smaller, outhouse where they were expected to strip and store all clothing and belongings before passing through a powerful "shower-bath" after which they entered a second room to dress in autoclaved sterile work-clothes. Entrance to the main building's clean area was through a closed linking corridor involving further decontamination procedures such as exposure to insecticides and ultra-violet light with each stage separated by an airlock (Figure 11.4). Nonetheless, excluded microbes soon took
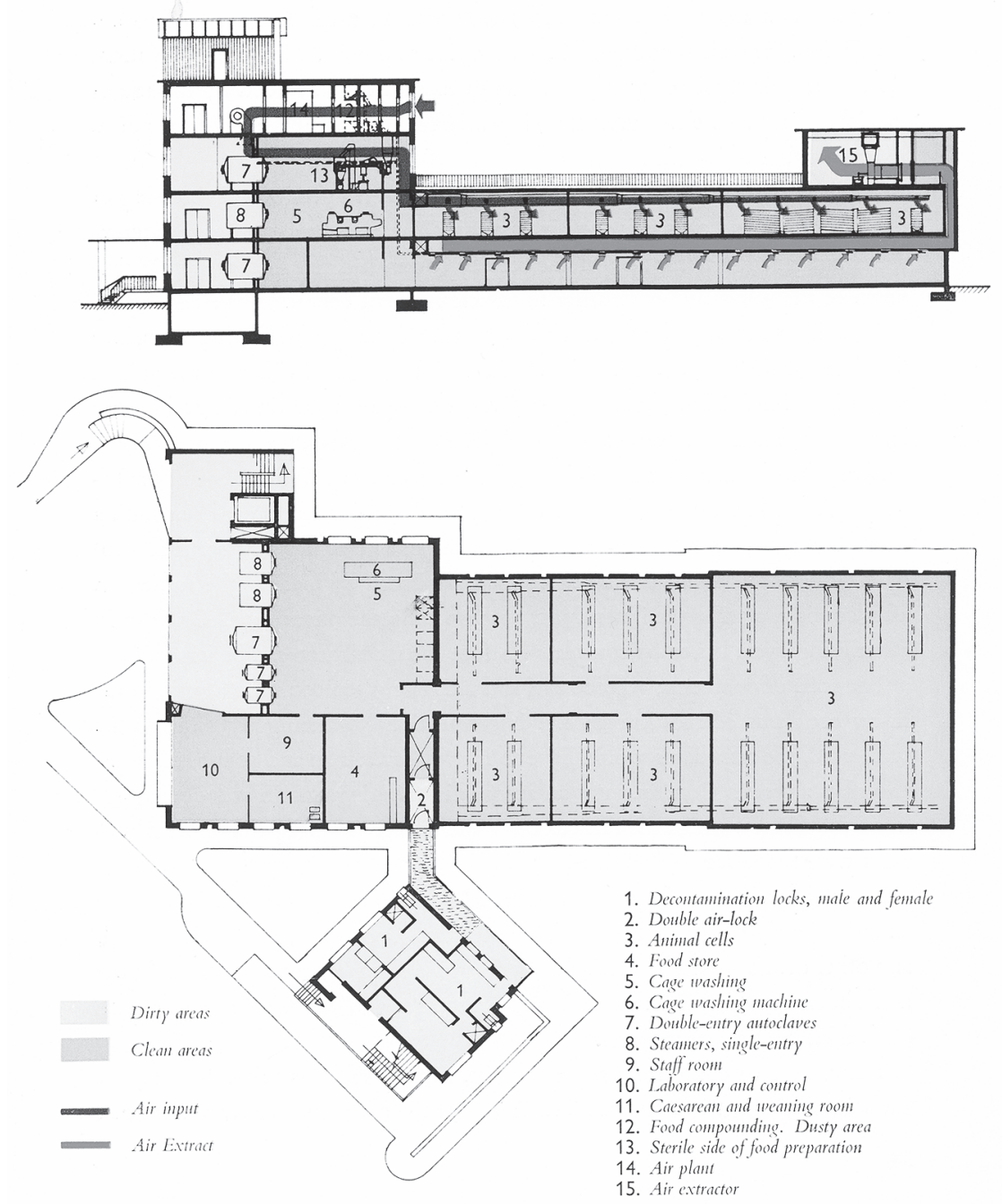

Figure 11.4 ICI Animal Breeding Unit

Source: I.C.I., n.d. 
up residence in the clean area; one of the earliest to make its presence felt was $B$. coli. With time, SPF animals proved to be highly susceptible to infection with human microbes, with one explanation being that their artificially adjusted microbial flora lacked competing microbes. Human Salmonella carriers, for instance, were identified as a threat to SPF colonies which, once infected, subsequently served as vectors spreading the problem to human carers (cf. Hull 1963). Similarly, humans were identified as reservoirs for Pseudomonas aeruginosa, which devastated SPF murine populations (Flynn 1963; Hammond 1963). Consequently, new surveillance techniques were introduced to identify human carriers of pathogens so that they could be removed from duty (Van de Waaij et al. 1963). At the ICI breeding unit, routine checks quickly revealed that the SPF colonies had come to harbor proteus species, coliform organisms, and Streptoccocus faecalis. By 1961, Pseudomonas pyocyaneus and a human type of Staphylococcus had also been introduced to the shared microbial ecology presumably by human carriers. In general, such intrusions were tolerated as the microbes concerned were not considered to be pathogenic. Nevertheless, the ability of microbes to penetrate a building designed to be microbially secure illustrates how infrastructures intended to isolate and thus prevent microbial exchanges worked simultaneously to reveal the full extent to which human, animal and material infrastructures co-existed as a shared microbial ecology.

In spite of these problems, ICI researchers universally reported that the new SPF standard of animals were "fitter in every way" (Davey 1962, 8). Nor were they alone. These new practices created new forms of life guaranteed to be free of specific pathogens. Once initial stocks were introduced (via surgical removal of progeny before birth and raising by germ-free foster parents within the clean area) the breeding unit was capable of producing 100,000 rats and 500,000 mice annually. SPF animals were found to be healthier, exhibiting greater fertility and an extended life span in comparison with conventional animals. They were also thought to be more physically robust, better able to endure stressful experimental procedures and tolerating higher doses of toxins. SPF status, for example, made mice and rats plausible species for long-term experiments (such as the US Food and Drug Agency's demand that food additives be studied for two years in at least two species) which had hitherto, through necessity, employed larger more expensive species (Davey 1962). As such, the making of SPF animals illustrates how care practices gradually attuned forms of life to better meet scientific need. In a sense, SPF animals embodied the values of the moral economy in that they better met the needs of science, of fiscal economy and of the perceived needs of animal welfare. By the end of the 1960s, SPF criteria had become an accepted standard for the majority of commonly used laboratory species (Anonymous 1969).

The ICI complex at Alderley Park reveals how concerns over the health, welfare, scientific utility and fiscal cost of laboratory animals, which together formed a coherent moral economy of care, were enacted through the macro-infrastructure of the animal house and laboratory. So critical was the need to control microbial relations to the moral economy of laboratory life that it came to dominate the design of modern research facilities in the decades after the close of 
the Second World War. Traditional methods of quarantine (through spatial distribution and material barriers) were enhanced by new techniques, technologies and infrastructures, which together drove the creation of new microbially managed ecologies. SPF technologies instantiated "second natures" that controlled and enhanced the shared multispecies microbial ecology of lived relations within these new spaces. Accordingly, the decade and a half following the close of the Second World War witnessed a radical shift in the meaning and ontology of what it was to be a laboratory animal. By the end of the 1960s, laboratory animals were precisely what their name suggested: new forms of life that were born of and for the laboratory. By giving material form to a specific moral economy, the macroinfrastructure of animal houses and laboratories literally institutionalized care practices that subsequently transformed the laboratory animal into a new form of life defined by their microbial loads and shared ecological relations.

\section{Care in the Cage: Materializing the Moral Economy of the Animal House}

Not all, however, possessed the capital for building the moral economy of animal care into the macro-infrastructure of animal house and laboratory architecture as did ICI. Such projects in general worked best when creating new facilities as opposed to adapting established buildings and/or animal stocks (the major obstacle being the latter possessed complex microbial ecologies that were difficult to erase). Consequently, alternative approaches to enacting moral economies of laboratory animal care were developed focused on micro-infrastructure such as the animal cage. In 1963, for instance, the University of Cambridge's mouse house developed an innovative cage design making use of a new plastic. Somewhat controversially, the plastic chosen could not withstand the heat of autoclaving. Describing the new cage, Margaret Wallace acknowledged the "hesitation by other laboratories" to use such plastics yet proposed nonetheless that it was "the cheapest plastic, least noisy [and] sterilization is usually unnecessary if hygiene is studied in cage design and all parts of the laboratory" (Wallace 1963, 69). Prior to the establishment of SPF as an expected health standard, many held the view that "a completely disease-free stock of laboratory animals is an impossible ideal" (Salaman 1956). From such a perspective, animal care was envisioned as a continuous and responsive activity, a practice that called for the dynamic management of the often conflicting needs that made up the moral economy of care (which variously included animal health and welfare, human labor, experimental requirements and economic considerations). Thus, it was perfectly acceptable to weaken one element of this constellation in favor of strengthening others that were of local importance. Whilst SPF techniques removed the risk of infection, almost entirely unless mistakes were made, it did so at a financial and labor cost that many, at least initially, felt unnecessary and/or impractical. Wallace described the five values that had shaped Cambridge's particular instantiation of the moral economy of care: (1) maximize animal health and breeding rates, (2) minimum demand on human labor, (3) 
materials of cage maximize 1 and 2 at the minimum of economic cost, (4) promote experimental utility, (5) materials to be conducive to a pleasant environment for the worker. Whilst some of these values could be productively balanced, rarely did progress in one area not have unforeseen consequences elsewhere. Materializing these values within the micro-infrastructure of animal houses and laboratories required calculated compromise. As different laboratories favored different ways of balancing the moral economy to suit local purposes, there was general agreement of "an urgent need for some experienced body to undertake either basic research on behavior of caged animals and the testing of designs" as "only then will standardization become possible" (Wallace 1963, 65). Wallace was not the first, nor the last to attach this caveat to their description of local practices. In 1949, for instance, a review of laboratory animal housing practice observed that "most workers express a preference for standard sizes but in regard to these same standard sizes, it appears that quot homines, tot sententiae" (Jones and Wood 1949, 194). There were as many standards as persons.

One obstacle to the development of shared standards and systematic knowledge was that animals responded unpredictably to novel circumstances and even the most controlled of environments contained a constellation of factors that could impact on an animal's make up. Even the smallest of events, such as the appearance of a stranger in the animal house, could detrimentally impact on animal welfare (recognized principally at the time through depressed reproduction rates). Dramatic change, such as moving an animal population from one room to another, had been known to prevent normal breeding for several months (Farris 1945, 4). Assessing the consequences of different technologies and practices of care was therefore far from straightforward. In the 1950s, for instance, there was a general trend to replace wooden cages with metal and wire mesh cages as the latter could be autoclaved and thus were presented as a hygienic intervention to deter cross-infection and promote health. Metal, unlike wood, was less likely to harbor parasites and pathogens. However, some found that certain species, particularly mice, were less productive in metal cages. One explanation for this was that mice preferred "darkness" resulting in recommendations for the continued use of traditional wooden boxes (Lane-Petter 1959, 28). Others attributed the problem to the colder environment, claiming that mice would reproduce normally if the overall temperature of the room was raised (Strong 1950, 84). Hence quot homines, tot sententiae; scope for interpretive flexibility ensured that were as many opinions as persons. Nevertheless, as the cage was gradually established as a core means to enact animal care, systematic knowledge of its properties and impact on animal health and welfare became increasingly important:

To keep an animal in a cage will inevitably modify its behaviour in several ways, not always to the disadvantage of the animal. Certain types or sizes of cage may affect the animal adversely, and offend both humanitarian considerations and also scientific requirements ... An unnecessarily large cage will 
take up so much room in the animal house that the already high cost of maintenance will be fruitlessly multiplied. A cage of dimensions smaller than those dictated by custom, conjecture, anthropomorphic misconception ... may not necessarily interfere with the well-being of its inmate. It is quite unjustifiable to assume that the bigger the cage, the better for the animal ... There is a great need for some real information on the subject. Cages are expensive items of equipment and there is such a multiplicity of design that standardization remains unattainable in the absence of precise knowledge: Yet standardization of, say mouse boxes, would reduce the cost considerably. (Lane-Petter 1953, 126-127)

Such calls reflected growing recognition of the difficulty of holding in productive tension the varied and often conflicting values that shaped moral economies of care as much as the challenge of enacting moral economies through material infrastructure. Custom, conjecture, and anthropomorphic misconceptions were no longer acceptable criteria for determining how these competing values should take material form in the cage. Instead, animals and their environments would become the object of study in themselves, objects studied, made and remade largely through practice. As a result, the cage ceased (if it ever had been) to serve merely as a means to an end, which is to say an epistemologically and morally empty object. Instead, the cage increasingly became a material embodiment of a range of moral, ethical, economic and epistemological concerns that together made up a moral economy of care.

Responses to the rodent preference for coprophagy demonstrate the way cages enacted moral economies of care. Separating animals from their feces appeared an obvious and necessary step toward establishing a hygienic and thus healthy animal house environment. One simple and effective means to achieve this was the introduction of cages with wire mesh flooring. This allowed feces to fall into a lower tray out of reach of the animal to be easily cleaned by the animal caretaker (or automatically flushed as at ICI). However, rodents were known to consume their own feces and it was unclear what if any impact preventing this practice might have on their health, welfare, reproductive efficiency and scientific utility. Understanding coprophagy's role was far from straightforward as various additional factors - such as the nutritional content of food, which varied across locations despite numerous standard formulations emerging - complicated coherent assessments. Further difficulties emerged in understanding the social role of coprophagy, as some rodents were known to eat feces from another's behind if housed in groups that allowed it. Within specific fields, such as nutritional research, coprophagy gained enhanced importance as it impacted directly on the object of research. Coprophagy introduced an uncontrolled source of nutrients, whilst its prevention risked working with an animal that departed from the norm in unspecified ways. Moreover, nutritional research's experimental designs routinely incorporated the removal and analysis of feces as a standard practice. Consequently, coprophagy spawned a lively research culture enacted through new forms of caging. Numerous variations of what came to be known as "anti- 
coprophagy" or "metabolism" cages were developed to separate rodents from feces. One popular design consisted of narrow wire-mesh cylinders connected to form a simple circular tunnel. This allowed rodents to crawl forward and obtain food but made coprophagy impossible by preventing turning within the tube (Chalam Metta et al. 1961, 474). The tubular coprophagy cage favored the needs of experimental science over the health and comfort of the animal as prolonged confinement restricted a range of "normal" behaviors (Lane-Petter 1957, 30). An alternative, designed by George Brownlee and used at the Wellcome Physiological Research Laboratories (UK), consisted of a cubic metal cage with a cylinder at the end of which a feeding cup was located. Rodents could enter the cylinder to feed but could not turn about within the cylinder, thus feces dropped through the wire mesh floor with little opportunity for consumption. This design attempted a better balance between animal health, welfare and experimental necessity by separating rodent from feces without overly restricting movement (Gorer 1947, 156). The distinction between the two lay not so much in the concept or aim but in the specific choices over how to enact the local moral economy through the materiality of the cage. As researchers looked first to local need, a multiplicity of cage designs emerged sustaining the role of custom, conjecture, and anthropomorphic misconceptions to shape the material instantiation of moral economies even as the work was conducted with the intent of systematically establishing shared standards of practice.

Concerns over coprophagy declined rapidly with the widespread adoption of SPF standards as the controlled microbial ecology of an SPF facility removed any health threat. However, the eventual acceptance of SPF animals as an expected standard in large part became possible once the technique could be enacted at the micro-infrastructural level of the cage. Work to this end began in the late 1950s with the recognition that traditional open-top cages, whilst efficient in allowing easy access to animals, also encouraged the transmission of pathogens. One of the first so-called "filter" cages was developed by Lisbeth M. Kraft at Yale for the purpose of investigating and eradicating a local endemic infection causing diarrhea in infant mice (Kraft 1958). Kraft's system used fiberglass mesh to establish a secure barrier preventing the free exchange of air between the cage and wider environment of the animal house (Figure 11.5). Accordingly, individual filter cages could only be opened within a large isolator fitted with its own clean air supply.

Through the 1960s, Kraft's filter cage was adapted to a myriad of new applications as it provided an affordable means to remove pathogens from animal houses without the economic costs required by macro-infrastructural SPF facilities such as that of ICI (e.g. Simmons et al. 1967). Nevertheless, whilst filter cages provided an effective means to enact a moral economy that prioritized freedom from infection it came at the cost of a basic animal care practice: Routine observation. Sealed in metal cylinders, animals could only be viewed by examination within a secure isolator - a labor-intensive activity that risked additionally stressing rodents. It was not until the advent of robust and affordable plastics in the 1970 s that a better balance could be struck between the pursuit of health and the observational needs of animal care. 




Figure 11.5 Original "Filter" cages designed by Kraft. The cage on the left is shown without the fiberglass filter lid; that on the right is the complete unit

Source: Kraft, 1958.

Attempts to make productive use of plastic within cage design had been made since at least the 1940s. However, plastic was initially prohibitively expensive and unable to compete with metal which, unlike early plastics, could withstand the high heat of the autoclave (Strong 1950, 86-87). Though the 1960s advances in plastic production produced first polycarbonate and later polysulfone, making possible affordable, lighter, warmer, and importantly transparent caging that allowed the observation of animals without their physical disturbance. By the mid-1970s, filtered roof techniques began to be combined with newly emerging plastic cages to produce an effective and affordable microbially secure microenvironment. One of the first widely adopted commercial examples was that of Robert Sedlacek (Sedlacek and Mason 1977) marketed as Lab Products Inc.'s "Micro-Isolator ${ }^{\mathrm{TM}}$ System." Within the "Micro-Isolator ${ }^{\mathrm{TM}}$ System" mice existed in a secure microbial environment separated from that of the wider animal facility. The adoption of isolation cages provided a simple material solution to previously complex ecological and practical relations. The SPF conditions of Micro-Isolator ${ }^{\mathrm{TM}}$ caging, for instance, rendered feces effectively "clean" rendering coprophagy a non-problem. 
Nevertheless, as with previous innovations, new material infrastructures produced new challenges to animal care demanding further innovation. Isolation cages effectively created microclimates that increased moisture accumulation and thus temperature relative to the room as a whole. Again, the attempt to create independent ecological environments served only to re-inscribe their codependence as increased temperatures within isolation cages necessitated lower temperatures within the wider animal house. Care practice continued to require the management of the whole. A more significant problem caused by the microclimate effect was the tendency for ammonia levels to detrimentally rise to the point at which mice were gradually suffocated by their own urine (for example Keller et al. 1989). Here again, local contingencies shaped experience. When developing the Micro-Isolator ${ }^{\mathrm{TM}}$ System, Sedlacek had not encountered this problem as he had worked with "germ-free" mice that lacked the urease bacteria required to convert urine into ammonia. Once more the complexity of microbial relations within the laboratory ecologies came to the fore as urine replaced feces as the primary health concern. In contemporary mouse facilities, this problem has been reduced by the development of Individually Ventilated Cage (IVC) systems where each isolation cage has its own regularly circulated air supply. Multiple IVC cages had emerged in the 1960s in response to various local needs. One early IVC was designed to allow work on dangerous pathogens to be pursued relatively safely by safeguarding researchers, technicians and animal carers from accidental exposure to infected animals (Cook 1968). Others, such as an IVC designed by Edwin P. Les of the Jackson Laboratory, Bar Harbor (Maine, USA) and Bill Thomas of Thoren Industries, was intended as a means to promote animal health and welfare and thus materialized a moral economy of animal care. ${ }^{4}$ As such, the IVC again illustrates the complexity of concerns and values that were enacted in the material form of the animal cage.

\section{Conclusion: The Materialization of Care}

The "cleaning up" of animals has been a prominent theme of this chapter. On her journey from cyborg to companion species concerns, Haraway paused to offer a twenty-one point program within which a "key question is who cleans up the shit in companion species relations?" (Haraway 2003, 79). We may accordingly propose that "cleaning up the shit" is an act of care. Whether by automatic systems integrated into the architecture of animal house buildings, such as the mechanical flushing away of feces and waste from animal cages within the SPF facilities at Alderley Park, or the physical separation of animal from feces using wire-mesh floored cages, removing shit was a critical concern for those who worked with and cared for laboratory animals. It was a concern that formed a central part of moral economies of animal care which, in various ways, came to be embedded in and practiced through the macro and micro material infrastructures of animal houses and laboratories. Cleaning up the shit was neither a simple practice nor was it without transformative consequence. Shit was host to a multitude of microbial species all of which had to be understood and managed through 
their relations with the wider laboratory ecology, human, animal and material alike. Choices had to be made as to which microbes were to be included or excluded from the shared ecologies of laboratory life, choices that balanced the competing concerns and values which shaped local moral economies of care. In some instances, competition for shit posed significant challenges. When feces became a matter of scientific interest, researchers laid claim to a resource that rodents utilized to meet little understood nutritional and possibly social needs. Competing demands were held in a productive tension by enacting these concerns through material infrastructures, stabilizing (for a time) animal care practices. As each new cage embodied and expressed a specific moral economy of care it also generated new challenges driving innovation and historical change.

Over time, the material infrastructures of the animal house and laboratory have been repeatedly configured and reconfigured in response to shifting moral economies of care. The changing material infrastructures of the laboratory animal house can be understood as having co-evolved with new forms of life (e.g. SPF animals), new animal care practices, new human identities (e.g. professional animal caretaker), research trajectories, and other factors that, cumulatively, made up a dynamic moral economy of care. Material infrastructures have facilitated the enactment of relations between forms of life that were recognized to possess insecure boundaries. From this perspective, the laboratory and animal house become lively relational sites where the process of becoming anew is always a potential. Material infrastructure can be seen as collaborative partners instantiating and shaping changing moral economies of laboratory life and labor. Material infrastructures, in sum, serve to intervene in processes of shared becoming. Understanding such processes, which would be to cultivate a reflective awareness of the multiple ways of practicing care through material infrastructures, would form one response to recent calls to theorize care as a "living technology with vital material implications for human and non-human worlds" (Puig de la Bellacasa 2011, 101).

\section{Notes}

1 Importantly, the focus of analysis is less the "laboratory" than the "animal house." This is an important distinction, historically, albeit one that has become less so in recent years as the boundary between the two has been eroded due to experimental procedures increasingly moving from a distinct laboratory space to what is now commonly known as the "Biological Services Facility."

2 Early studies of the epidemiology of laboratory animals had reported little more than the complexity of the problem (e.g. Greenwood et al. 1936). Without precise epidemiological knowledge, it was difficult to meaningfully attribute a disease outbreak to new microbes having entered the microbial ecology of the animal house or whether the introduction of new animals had initiated a process of social or environmental change that triggered an already present latent infection to manifest as disease.

3 Nevertheless, the animal house continued to be secondary to the laboratory. Writing in 1959, William Lane-Petter complained of "the bitter experience of many that this consideration has all too often been overlooked. In the planning, any surplus on the overall budget has been grudgingly given over to animals, which have suffered on the 
way by any economies that are forced upon the planners. The wise director takes his 10 or 15 percent at the beginning and builds his animal house before the laboratory. He can then establish it while the laboratory is being completed, so that his staff can move in when the painters move out and have animals ready to hand" (Lane-Petter 1959, 193).

4 Marketed as the "Maxi-Miser® Positive Individually Ventilated System (PIV)" from 1978. Thoren Industries was the first commercial company to develop warm surface plastic cages in 1953 .

\section{References}

Anonymous (1969) “Animal for research,” Lancet, 7620: 582.

Chalam Metta, V., Nash, L., and Connor Johnson, B. (1961) “A tubular coprophagy cage for the rat. Journal of Nutrition 74: 473-476.

Clarke, A., Mamo, L., and Fosket, J.R. (2010) Biomedicalization: Technoscience, Health, and Illness in the U.S. Durham, NC: Duke University Press.

Cook, R.O. (1968) "New Ventilated Isolation Cage," Applied Microbiology, 16: 762-771.

Daston, L. (1995) “The Moral Economy of Science," Osiris, 10: 2-24.

Davey, D.G. (1959) "Establishing and Maintaining a Colony of Specific Pathogen Free Mice, Rats and Guinea-Pigs," Quality in Laboratory Animals (Collected Papers Laboratory Animals Bureau 8). London: MRC, pp. 17-34.

Davey, D.G. (1962) "The Provision and Use of Pathogen-free Laboratory Animals," Proceedings of the Royal Society of Medicine, 55: 253-263.

Farris, E.J. (1945) "Introduction to the conference on animal colony maintenance," Annals of the New York Academy of Sciences, 46: 3-4.

Flynn, R.J. (1963) "Pseudomonas Aeruginosa Infection and Its Effects on Biological and Medical Research," Laboratory Animal Care, 13: 1-6.

Gorer, P.A. (1947) "The Mouse," in A.N. Worden (ed.), The UFAW Handbook on the Care and Management of Laboratory Animals. London: Bailliere, Tindall and Cox, pp. 150-167.

Greenman, M.J., and Duhring, F.L. (1931) Breeding and Care of the Albino Rat. Philadelphia: Wistar Institute.

Greenwood, M., Hill, A.B., Topley, W.W.C., and Wilson, J. (1936) Experimental Epidemiology: Special Report Medical Research Council no. 209. London, HMSO.

Hammond, C.W. (1963) "Pseudomonas Aeruginosa Infection and Its Effects on Radiobiological Research," Laboratory Animal Care, 13: 6-11.

Haraway, D.J. (2003) "Cyborgs to Companion Species: Reconfiguring Kin in Technoscience," in D. Ihde and E. Selinger (eds), Chasing Technoscience. Bloomington: Indiana University Press, pp. 58-82.

Haraway, D.J. (2008) When Species Meet. Minneapolis: University of Minnesota Press.

Howie, J.W. (1956) "Chairman's Remarks," in Infections in Laboratory Animals (Collected Papers Laboratory Animals Bureau 4). London: MRC, pp. 5-6.

Hull, T.G. (1963) Diseases Transmitted from Animals to Man (5th edn). Springfield, IL: Charles C. Thomas.

I.C.I. (n.d.) Pharmaceutical Research. Birmingham, UK: Kynoch Press.

Jones, J.I.M., and Wood, E.C. (1949) "The Housing of Laboratory Animals," Journal of Hygiene, 47: 190-196.

Keller, L.S.F., White, W.J., Snider, M.T., and Lang, C.M. (1989) “An Evaluation of Intra- 
Cage Ventilation in Three Animal Caging Systems," Laboratory Animal Science, 39: 237-242.

Kirk, R.G.W. (2012) “'Standardization through Mechanization': Germ-Free Life and the Engineering of the Ideal Laboratory Animal," Technology and Culture, 53: 61-93.

Kohler, R.E. (1994) Lords of the Fly: Drosophila Genetics and the Experimental Life Chicago: University of Chicago Press.

Kraft, L.M. (1958) "Observations on the Control and Natural History of Epidemic Diarrhea of Infant Mice," Yale Journal of Biology and Medicine, 31: 121-137.

Lane-Petter, W. (1953) "Some Behavioural Problems in Common Laboratory Animals," $B J A B, 1: 124-127$.

Lane-Petter, W. (1957) “Animal House Equipment," in A.N. Worden and W. Lane-Petter (eds), The UFAW Handbook on the Care and Management of Laboratory Animals. London: UFAW, pp. 23-57.

Lane-Petter, W. (1959) "The Place of Laboratory Animals in the Scientific Life of a Country," Impact of Science on Society, 9: 178-196.

Lane-Petter, W. (1963) "Discussion," The Choice of Experimental Animal: Laboratory Animals Centre Collected Papers (vol. 12). London: MRC, pp. 54-55.

Lane-Petter, W. (1966) "Sophisticated Laboratory Animals," in I. Gilliland and J. Francis (eds), The Scientific Basis of Medicine: Annual Reviews. London: Athlone, pp. 54-70.

Latour, B. (1992) "Where are the Missing Masses? Sociology of a Few Mundane Artefacts," in W. Bijker and J. Law (eds), Shaping Technology - Building Society: Studies in Sociotechnical Change. Cambridge, MA: MIT Press, pp. 225-229.

Latour, B. (2002) "Morality and Technology The End of the Means," Theory, Culture and Society, 19: 247-260.

Law, J., and Singleton, V. (2005) “Object Lessons,” Organization, 12: 331-355.

Mol, A. (2002) The Body Multiple: Ontology in Medical Practice. Durham, NC: Duke University Press.

Puig de la Bellacasa, M. (2011) "Matters of Care in Technoscience: Assembling Neglected Things," Social Studies of Science, 41: 85-106.

Salaman, M.H. (1956) "Discussion," in Infections in Laboratory Animals (Collected Papers Laboratory Animals Bureau 4). London: MRC, p. 17.

Sedlacek, R.S., and Mason, K.A. (1977) "A Simple and Inexpensive Method for Maintaining a Defined Flora Mouse Colony," Laboratory Animal Science, 27: 667-670.

Simmons, M.L., Richter, C.B., Franklin, J., and Tennant, R.W. (1967) "Prevention of Infectious Diseases in Experimental Mice," Proceedings of the Society for Experimental Biology and Medicine, 126: 830-837.

Strasser, B.J. (2011) “The Experimenter's Museum: GenBank, Natural History, and the Moral Economies of Biomedicine," Isis, 102: 60-96.

Strong, L.C. (1950) "The Care of Experimental Mice," in E. J. Farris (ed.) The Care and Breeding of Laboratory Animals. New York: John Wiley.

Wallace, M.E. (1963) "Cage Design Principles, Practice and Cost," Journal of the Animal Technicians Association, 14: 65-72.

Woolgar, S., and Lezaun, J. (2013) "The Wrong Bin Bag: A Turn to Ontology in Science and Technology Studies," Social Studies of Science, 43: 321-340.

Van de Waaij, D., Zimmerman, W.M.T., and van Bekkum, D.W. (1963) "An Outbreak of Pseudomonas Aeruginosa Infection in a Colony Previously Free of This Infection," Laboratory Animal Care, 13: 46-53. 
